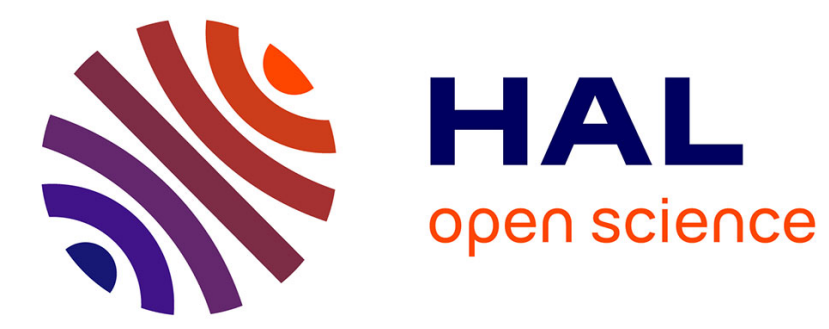

\title{
On the Magnetisation by Spin Rotation in Dense or Heterogeneous Soft Magnetic Materials
}

P. Le Fur, A. Konn, Philippe Laurent, M. Le Floc'H, F. Le Floc'H, P. Binon

\section{To cite this version:}

P. Le Fur, A. Konn, Philippe Laurent, M. Le Floc'H, F. Le Floc'H, et al.. On the Magnetisation by Spin Rotation in Dense or Heterogeneous Soft Magnetic Materials. Journal de Physique IV Proceedings, 1997, 07 (C1), pp.C1-545-C1-546. 10.1051/jp4:19971224 . jpa-00254897

\section{HAL Id: jpa-00254897 https://hal.science/jpa-00254897}

Submitted on 1 Jan 1997

HAL is a multi-disciplinary open access archive for the deposit and dissemination of scientific research documents, whether they are published or not. The documents may come from teaching and research institutions in France or abroad, or from public or private research centers.
L'archive ouverte pluridisciplinaire HAL, est destinée au dépôt et à la diffusion de documents scientifiques de niveau recherche, publiés ou non, émanant des établissements d'enseignement et de recherche français ou étrangers, des laboratoires publics ou privés. 


\title{
On the Magnetisation by Spin Rotation in Dense or Heterogeneous Soft Magnetic Materials
}

\author{
P. Le Fur, A.M. Konn*, P. Laurent*, M. Le Floc'h*, F. Le Floc'h** and P. Binon***
}

I.S.E.M., Place Georges Pompidou, 83000 Toulon, France

* Laboratoire d'Électronique et des Systèmes de Télécommunication (UMR 1329) - UFR Sciences, BP. 809, 6 avenue Le Gorgeu, 29285 Brest cedex, France

** URA 322 du CNRS, UFR Sciences, BP. 809, 6 avenue Le Gorgeu, 29285 Brest cedex, France

*** SAGEM/Ferrites, 03106 Montluçon cedex, France

\begin{abstract}
Results of the literature seem to be consistent with our experience of the soft magnetic composite materials to advance that they magnetize by spin rotations rather than by domain wall motions. We have thus proposed to express the effective magnetic susceptibility as varying with the magnetic fraction through a parameter of microstructural origin $(\mathrm{N})$, and a factor connected to the magnetic character of the substance $\left(\chi_{i}\right)$. This work shows that $\chi_{i}$ may be represented by $\chi_{\text {rot }}$ (rotational magnetization), and not by the susceptibility of the bulk matter. Some compositions of ferrites (Ni-ferrites, YIG) for which $\chi_{\text {rot }}$ was known, gave a good confirmation of the above assumption. For other materials, it was necessary to determine $\chi_{\text {rot }}$ experimentally. The technique used is described briefly. It has been sucessfully tested on the ferrites mentioned above. Owing to this calibration, the apparatus is ready now to measure $\chi_{\text {rot }}$ on various dense magnetic matters before they are ground then mixed with resin to be investigated as a function of the magnetic load with the intent to extract the parameter $\chi_{\mathrm{i}}$. This study is very important for all the applications in which both high susceptibtilities and wide frequency bands are required simultaneously.
\end{abstract}

Previous works [1] concerning the initial susceptibility of soft magnetic composite materials (pressed mixtures of non-magnetic and magnetic powders with particles of a few ten microns), seem to show, in low-to-medium volume fractions $(<0.6)$, that the magnetization in weak fields could satisfactorily be interpreted as a rotational process rather than a domain wall mechanism.

The first experimental observation goes probably back to Rado et al. [2] who noted in bulk $\mathrm{Mg}$-ferrites two peaks of losses (a low frequency peak due to the domain wall resonance and a high frequency peak due to the spin resonance), but only the peak of the spin rotation when the ferrites were grinded then dispersed in paraffin. Five years later, Brown and Gravel [3] did a similar observation on partially formed $\mathrm{Ni}$-ferrites confirming that only the rotational mechanism was visible in spite of a matter density sufficient to allow the appearance of domain walls. So, in grain structures containing air-gap-like defects as those currently encountered in powders, chemically unfinished substances or very porous materials (all the cases of non uniform saturation magnetization [4]), multi-domains probably exist but the walls must be strongly hindered by magnetostatic energies connected to the pseudo-isolated particles. The fact that in non-conducting ferrimagnetic composite materials, the susceptibility is often found as independent of the grain size [5], is a further argument in consideration of the only rotational process. An analytical expression to describe the effective susceptibility $\chi$ in soft magnetic composite materials as a function of the volume fraction $C$ of the magnetic phase, has been proposed and sucessfully tested experimentally [1]. The relation based on an "average field" assumption is given below:

$$
(1-N) \chi^{2}+\left[1+(N-C) \chi_{i}\right] \chi-C \chi_{i}=0
$$

$\mathrm{N}$ characterizes the average demagnetizing effect in the measurement direction, and $\chi_{\mathrm{i}}$ (the subject of the paper) is introduced to take the intrinsic properties of the magnetic part into account. Eq.(1) agrees surprisingly with experimental data provided the rotational susceptibility $\chi_{\text {rot }}$ (Snoek's law-type relation) was prefered to the "bulk susceptibility" to play the role of $\chi_{\mathrm{i}}$. Fig. 1 -a gives two examples, one for pure iron (ferromagnetic particles of $3 \mu \mathrm{m}$ ), the other for YIG (ferrimagnetic particles of $40 \mu \mathrm{m}$ ). The better fit between experimental values and those derivated from $\mathrm{Eq} .(1)$, has led to keep $\chi_{\mathrm{i}}=25(\mathrm{~N}=0.25)$ for iron, and $\chi_{\mathrm{i}}=$ $12(\mathrm{~N}=0.25)$ for YIG. By another way, studies concerning the natural spin resonance on one hand, and the quasistatic susceptibility as a function of the grain sizes in bulk polycrystalline YIG on the other hand [6,7], have shown that the rotational susceptibility was equal to 12 . Unfortunately, we have no equivalent informations for iron, but the use of the Snoek's relation $\left(\chi_{\text {rot }}=I_{s} / 3 \mu_{0} K_{1}\right.$ with $\mathrm{I}_{S}=2.16 \mathrm{~T}$ and $\mathrm{K}_{1}=+4.210^{4} \mathrm{~J} \cdot \mathrm{m}^{-3}$ [8] $)$ gives 29 (to compare with the result of Fig. 1-a). Fig. 1-b shows how the nature of the magnetic phase can act on the magnetic behaviour of the composite material. - 1: $\chi_{\mathrm{i}}$ varies in a wide range - 2: The Ni-ferrite composite has a low $\chi_{i}$ in agreement with the low $\chi_{\text {rot }}$ of the bulk material $\left(\chi_{\text {rot }}=4\right.$ [9] $)$ - 3: The Super-Sendust 
composite (metallic alloy with $87.3 \% \mathrm{Fe}, 4.2 \% \mathrm{Al}, 5.3 \% \mathrm{Si}$ and $3.2 \% \mathrm{Ni}$ ) known and used in industrial applications for its particularly low anisotropy has the highest $\chi_{i}$. Can $\chi_{i}=\chi_{\text {rot }}$ be considered as a general relation?

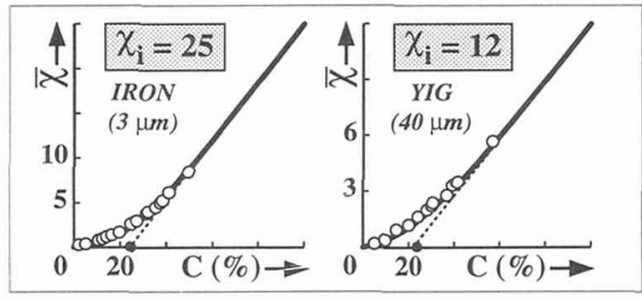

a)

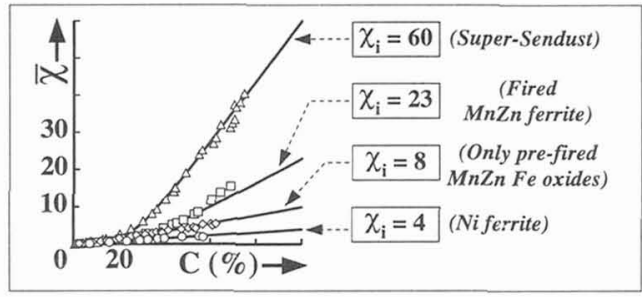

b)

Fig. 1 - Comparison between theory (Eq. 1) and experimental results for different kinds of magnetic matters : $\chi_{\mathrm{i}}$ follows the variations of $\chi_{\text {rot }}$.

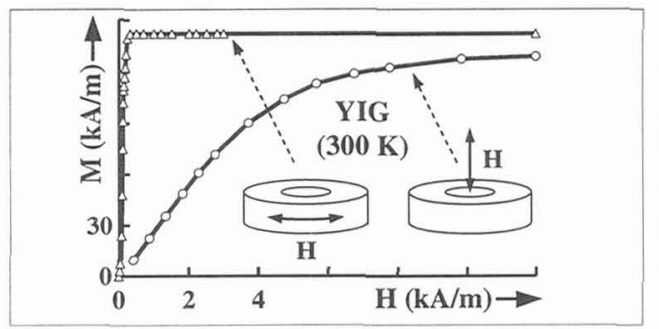

a)

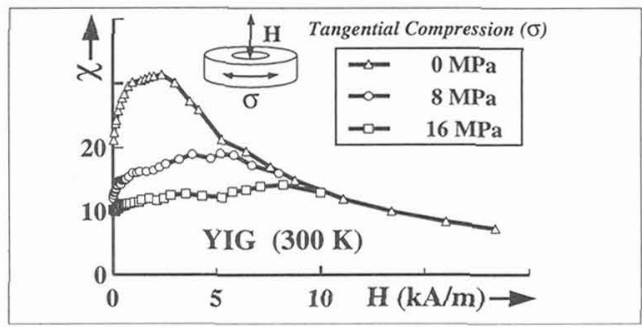

b)

Fig. 2 - (a) : Magnetization curves in both the "easy" (ring circumferences) and "hard" (revolution axis of the flat sample accurately inserted in a high permeability magnetic circuit) directions for a polycrystalline soft ferrite obeying the "magnetic-ring concept [6] - (b) : On ordinary materials, magnetic domains develop in any direction. Magnetization in the axial direction contains domain wall contributions which can easily be canceled by a stress $\sigma$ applied in the ring directions. This technique is a good way to separate the mechanisms and approach the rotational magnetization.

Many different compositions in soft ferrites exist which could give an access to a wide range of different values of $\chi_{\text {rot }}$. Actually, the lack of data concerning this parameter has led us to imagin a technical procedure in order to extract the rotational part from the total susceptibility of sintered samples. The principles of the method are presented in the following section.

Many works have been dealt with the study of the magnetization processes along the circumferences of ring-shaped ferrites. All of them concluded that in materials of high microstructural quality, the $180^{\circ}$ domain walls spontaneously acquired a ring-like distribution [6]. Starting from this idea that all the magnetic moments are effectively aligned along the circles of the sample, a magnetic field applied in the revolution axis (perpendicular direction), must be able to rotate the moments so that $\chi_{\text {rot }}$ becomes accessible directly. In this way, The flat ring sample is accurately inserted in the air-gap of an alternating elctromagnet of high intrinsic permeability. The susceptibility is measured by a classical flux method from the analysis of the magnetization curve from the zero magnetization to saturation. Fig. 2-a illustrates the difference typically observed between magnetization in the socalled easy-direction" (ring lines) and magnetization in the "hard direction" (revolution axis). In fact, actual materials, even with a good microstructure (defect-free grains), have not exactly the ideal domain wall configuration mentioned above. It is then necessary to use a compressive stress $(\sigma)$ applied along the ring lines to improve the toroidal alignement [10]. The decrease of susceptibility easily visible in Fig. 2-b comes from the stress application. In fact, it corresponds to the removal of the domain wall contribution. For $\sigma=16 \mathrm{MPa}$, the rotational behaviour can be considered as reached (Note that the susceptibility takes then the expected value). The method has been also tested on Ni-ferrites. The results found on this type of materials $\left(\chi_{\text {rot }}=4\right)$ is in good agreement with those of the literature [9] and also with Fig. 1-b. In the future, the technique will be applied at various ferrites and magnetic metals before they are transformed in composites to continue to test the validity of Eq.1.

\section{References.}

[1] Le Floc'h M., Mattei J.L.,Laurent P., Minot O. and Konn A.M., J. of M.M.M. 140-144 (1995) 2191-2192

[2] Rado G.T., Wright R.W. and Emerson W.H., Phys. Rev. 80 (1950) 273

[3] Brown G.T. and Gravel C.L., Phys. Rev. 97 (1955) 55

[4] Schlömann E., J. of Appl. Phys. 38 (1967) 5027-5034

[5] Nakamura T., Tsutaoka T. and Hatakeyama K., J. of M.M.M. 138 (1994) 319-328

[6] Globus A., J. de Phys. (Suppl. C1), (1977) 1-15

[7] Cagan V., Pascard H. and Globus A., J. of M.M.M. 15-18 (1980) 555-556

[8] Chikazumi S., "Physics of Magnetism", John Wiley and Sons, N.Y. (1964) pp. 261-264

[9] Globus A., C.R. Acad. Sc. Paris, 257 (1963) 1752

[10] Le:Floc'h M., J. Appl. Phys. 66 (1989) 1279-1284 